\title{
Treatment of mild persistent asthma by cutaneous electronic stimulation
}

\section{To the Editors:}

The Global Initiative for Asthma (GINA) has emphasised the importance of assessing control in response to treatment in grading asthma severity [1]. However, many asthma patients are inadequately controlled despite conventional treatment. GINA also recognises a potential role for complementary medicine in asthma management [1]. Fenzian ${ }^{\mathrm{TM}}$ (Eumedic Ltd, Hungerford, UK) is a device that provides low current cutaneous electronic stimulation (CES) and is Food and Drug Administration licensed under the category of minimal risk (Device \# 21 FR 882.5890) for biofeedback and treatment of pain. Biofeedback might influence bronchial smooth muscle constriction or perception of asthma control. We examined the hypothesis that CES, added to conventional treatment over 6 weeks, improves asthma control, pulmonary function, symptoms and reliance on rescue bronchodilator therapy in patients with persistent asthma.

In total, 20 subjects were recruited (nine males and 11 females), aged 18-65 yrs with a clinical history of mild-to-moderate persistent asthma for $\geqslant 3$ months [2] and forced expiratory volume in $1 \mathrm{~s}$ (FEV1) between $50 \%$ of predicted and the lower

TABLE 1 Baseline characteristics of the subjects

\begin{tabular}{|c|c|c|}
\hline & Sham & Fenzian $^{\mathrm{TM}}$ \\
\hline Age yrs & $45.4 \pm 15.8$ & $46.8 \pm 14.8$ \\
\hline Height m & $1.70 \pm 0.14$ & $1.70 \pm 0.05$ \\
\hline Weight kg & $79.3 \pm 16.8$ & $80.4 \pm 15.8$ \\
\hline FEV $_{1}{ }^{\#} \mathbf{L}$ & $2.32 \pm 0.7$ & $2.35 \pm 0.5$ \\
\hline FEV 1 \% reference & $70.8 \pm 10.7$ & $72.8 \pm 9.5$ \\
\hline PostBD FEV 1 L & $2.56 \pm 0.8$ & $2.67 \pm 0.8$ \\
\hline $\mathrm{FVC}^{\#} \mathrm{~L}$ & $3.28 \pm 1.0$ & $3.54 \pm 1.0$ \\
\hline FVC $\%$ reference & $80.2 \pm 11.5$ & $86.5 \pm 14.3$ \\
\hline PostBD FVC L & $3.38 \pm 1.0$ & $3.80 \pm 1.3$ \\
\hline $\mathrm{FEV}_{1 / \mathrm{FVC}} \%$ & $71.7 \pm 9.0$ & $68.4 \pm 11.4$ \\
\hline PostBD FEF25-75\% L. $\mathrm{s}^{-1}$ & $2.53 \pm 1.04$ & $1.97 \pm 0.76$ \\
\hline Asthma control ACQ & $1.69 \pm 0.89$ & $1.83 \pm 0.89$ \\
\hline AM PEF L. $\min ^{-1}$ & $347 \pm 77$ & $354 \pm 120$ \\
\hline PM PEF L. $\min ^{-1}$ & $349 \pm 75$ & $369 \pm 121$ \\
\hline AM BD use puffs & $0.30 \pm 0.78$ & $0.38 \pm 0.78$ \\
\hline PM BD use puffs & $0.37 \pm 0.98$ & $0.75 \pm 1.19$ \\
\hline
\end{tabular}

Data are presented as mean $\pm \mathrm{SD}$. At visit 1 (baseline), spirometry was performed three times with 30-min intervals between sets of measurements. FEV1: forced expiratory volume in $1 \mathrm{~s}$; BD: bronchodilator; FVC: forced vital capacity; FEF $25-75 \%$ : forced expiratory flow at $25-75 \%$ of FVC; ACQ: Asthma Control Questionnaire: AM: morning; PEF: peak expiratory flow; PM: afternoon. ${ }^{\#}$ : means of the best values from each of the three sets; " : reference values are derived from National Health and Nutrition Examination Survey III [5]. Fenzian ${ }^{\mathrm{TM}}$ is manufactured by Eumedic Ltd (Hungerford, UK). limit of normal [3]. They reported using short-acting bronchodilator therapy on $\geqslant 4$ days in 2 weeks. Their treatment regimen was otherwise stable consisting of bronchodilators alone or in combination with inhaled corticosteroids. None had evidence of recent respiratory tract infection. The study was approved by the Institutional Review Board (Human Subjects Protection Committee) of the University of California (Los Angeles, CA, USA) and each subject gave written informed consent.

The design was a single-blind, parallel-group study with two baseline visits, 4 weeks apart to ensure clinical stability. Subjects were randomised 1:1 to active or sham treatment consisting of 14 sessions over 6 weeks using a Fenzian ${ }^{\mathrm{TM}}$ device or an identical but inactivated device. We endeavoured to eliminate treatment and assessment bias. The study personnel who performed the assessments, including pulmonary function tests and administration of questionnaires, were

\section{TABLE 2 Changes in physiological measures and symptom assessments after 6 weeks of Fenzian $^{\mathrm{TM}}$ or sham treatment}

\begin{tabular}{|c|c|c|c|}
\hline & Sham & Fenzian $^{\mathrm{TM}}$ & p-value \\
\hline FEV $1 \mathrm{~mL}$ & $-28 \pm 7$ & $74 \pm 7$ & 0.281 \\
\hline FVC $\mathrm{mL}$ & $-21 \pm 7$ & $95 \pm 7$ & 0.261 \\
\hline FEF $25-75 \% L \cdot s^{-1}$ & $-0.18 \pm 0.14$ & $0.25 \pm 0.14$ & 0.033 \\
\hline isoFEF $25-75 \% \mathrm{~L} \cdot \mathrm{s}^{-1}$ & $-0.10 \pm 0.21$ & $0.09 \pm 0.20$ & 0.507 \\
\hline TDI & $-0.1 \pm 0.8$ & $1.8 \pm 0.7$ & 0.176 \\
\hline Asthma control ACQ & $0.16 \pm 0.22$ & $-0.55 \pm 0.22$ & 0.032 \\
\hline Asthma symptoms ASUI & $-0.04 \pm 0.05$ & $0.03 \pm 0.05$ & 0.279 \\
\hline Quality of life AQLQ & $-0.04 \pm 0.23$ & $0.38 \pm 0.21$ & 0.183 \\
\hline Quality of life SF-12 & $0.95 \pm 0.98$ & $1.07 \pm 0.93$ & 0.258 \\
\hline AM PEF L. $\min ^{-1}$ & $-2.8 \pm 4.8$ & $10.5 \pm 4.8$ & 0.029 \\
\hline AM BD use puffs & $0.16 \pm 0.07$ & $-0.25 \pm 0.07$ & $<0.001$ \\
\hline AM symptoms & $0.21 \pm 0.07$ & $-0.06 \pm 0.07$ & 0.338 \\
\hline PM PEF L. $\min ^{-1}$ & $1.95 \pm 5.07$ & $5.30 \pm 4.88$ & 0.278 \\
\hline PM BD use puffs & $0.03 \pm 0.10$ & $-0.58 \pm 0.10$ & $<0.001$ \\
\hline PM symptoms & $0.00 \pm 0.11$ & $-0.17 \pm 0.11$ & 0.120 \\
\hline AM dyspnoea & $0.76 \pm 0.63$ & $2.43 \pm 0.53$ & $<0.001$ \\
\hline PM dyspnoea & $0.66 \pm 0.64$ & $1.08 \pm 0.55$ & 0.052 \\
\hline Daily dyspnoea & $1.51 \pm 1.17$ & $3.57 \pm 0.98$ & $<0.001$ \\
\hline
\end{tabular}

Data are presented as mean $\pm \mathrm{SD}$, unless otherwise stated. FEV1: forced expiratory volume in $1 \mathrm{~s}$; FVC: forced vital capacity; FEF25-75\%: forced expiratory flow at $25-75 \%$ of $\mathrm{FVC}$; isoFEF $25-75 \%$ : forced expiratory flow between isovolumes of 25 and $75 \%$ of FVC; TDI: transition dyspnoea index; ACQ: Asthma Control Questionnaire; ASUI: Asthma Symptom Utility Index; AQLQ: Asthma Quality of Life Questionnaire; SF-12: Short-Form 12; AM: morning; PEF: peak expiratory flow; BD: bronchodilator; PM: afternoon. Significance tested by mixed effects models except isoFEF25-75\% and TDI which were compared by t-test. Fenzian ${ }^{T M}$ is manufactured by Eumedic Ltd (Hungerford, UK). 

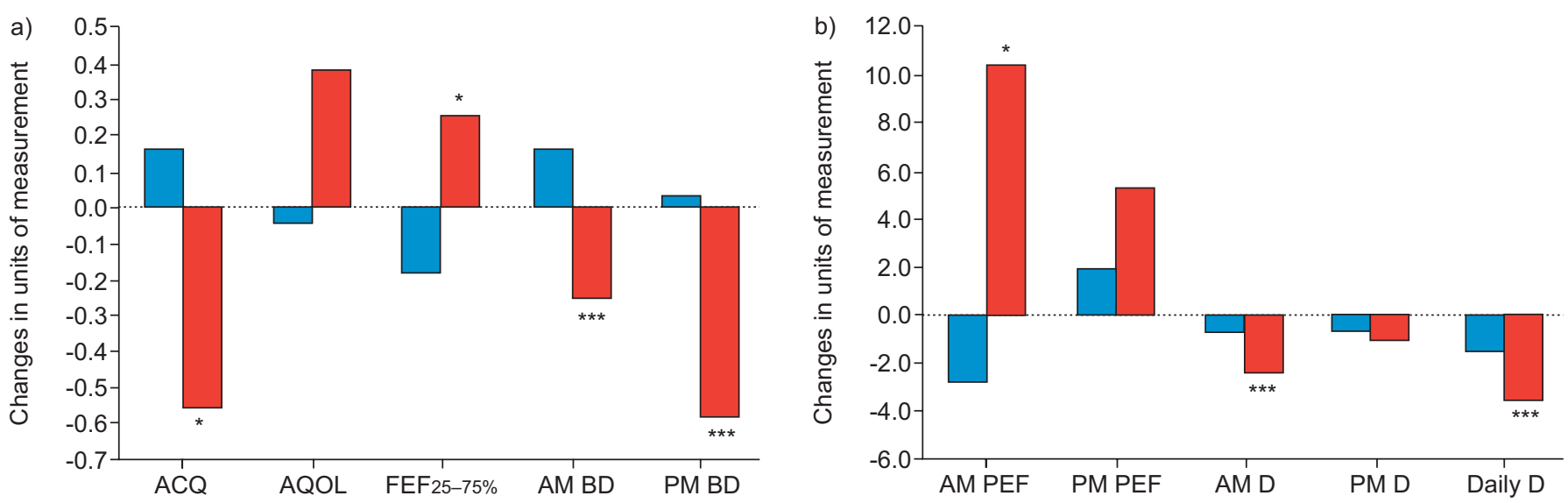

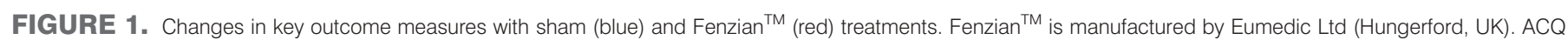
Asthma Control Questionnaire (a reduced score indicates improvement); AQOL: Asthma Quality of Life; FEF: forced expiratory flow between 25 and $75 \%$ of forced vital capacity $\left(L \cdot S^{-1}\right)$; AM BD: morning bronchodilator use (puffs); PM BD: afternoon bronchodilator use (puffs); AM PEF: morning peak expiratory flow $\left(L \cdot m^{-1}\right)$; PM PEF: afternoon peak expiratory flow $\left(L \cdot \mathrm{min}^{-1}\right)$; $A M \mathrm{D}$ : morning dyspnoea score; PM D: afternoon dyspnoea score; Daily $\mathrm{D}$ : daily dyspnoea score. ${ }^{*}$ : $p<0.05$; ${ }^{* * *}: \mathrm{p}<0.001$.

blinded as to whether the subject received active or sham treatment. The personnel administering the treatments obviously could not be blinded but care was taken to follow similar treatment routines in each group.

Asthma control, symptoms and quality of life were assessed using the Asthma Control Questionnaire (ACQ) [4], Asthma Symptom Utility Index [5], Asthma Quality of Life Questionnaire and Short Form-12 [6]. Subjects recorded the best of three peak flow measurements twice daily along with symptoms (breathlessness, chest tightness, cough, wheezing) and albuterol use on diary cards (AM-2 Asthma Monitor; Cardinal Health, Yorba Linda, CA, USA). Baseline characteristics were well matched between groups as seen in table 1 . Significant differences in physiological measures and questionnaires were not detected between visits 1 and 2 verifying clinical stability.

Changes in key outcome measures with sham and Fenzian ${ }^{\text {TM }}$ treatments are shown in table 2 and figure 1. With CES we found significant improvements in morning peak flow (from 349 to $360 \mathrm{~L} \cdot \mathrm{min}^{-1} ; \mathrm{p}=0.029$ ), morning bronchodilator use (from 0.55 to 0.30 puffs; $\mathrm{p}<0.001$ ), afternoon bronchodilator use (from 1.06 to 0.48 puffs; $\mathrm{p}<0.001$ ), and a composite of daily symptoms including breathlessness, chest tightness, cough and wheezing by Likert scales $(p<0.001)$. Breathlessness was also assessed using the dyspnoea index of MAHLER et al. [7]. Transition dyspnoea index was +1.8 with CES but unchanged with sham treatment. These improvements were accompanied by a significant improvement in asthma control by the ACQ $(p=0.023)$. Evaluation of the ACQ against GINA and National Institutes of Health (NIH) guidelines determined a cut-off point of 1.50 as identifying patients whose asthma is not well controlled, with a positive predictive value of 0.88 [8]. Thus both groups of subjects were not well controlled on entry into the current study. Those treated with CES showed an improvement in ACQ score from 1.83 to 1.30, i.e. became well controlled, whereas those receiving sham treatments showed deterioration in ACQ score from 1.69 to 1.84 .
Spirometry was performed three times at each visit. There were nonsignificant differences in the changes of FEV1 $(102 \mathrm{~mL})$ and forced vital capacity (FVC; $116 \mathrm{~mL}$ ) between the groups favouring CES. Forced expiratory flow at $25-75 \%$ of FVC increased by $0.25 \mathrm{~L} \cdot \mathrm{s}^{-1}$ with CES but decreased by $0.18 \mathrm{~L} \cdot \mathrm{s}^{-1}$ in controls $(\mathrm{p}=0.033)$.

This sham-controlled study shows proof of concept that CES with Fenzian ${ }^{\mathrm{TM}}$ might offer a novel alternative to conventional pharmacotherapy in patients with mild persistent asthma and perhaps an adjunct therapy for patients with more severe disease. We found a consistent pattern of improved asthma symptoms, including dyspnoea, and reduced bronchodilator use with small changes in airway function. The mechanism of action remains unknown but biofeedback could induce relaxation of bronchial smooth muscle or changes in the perception of asthma symptoms through central nervous system mechanisms.

\section{C.B. Cooper*, W.J. Boscardin", J.R. Colthurst ${ }^{\top}$ and E.C. Kleerup*}

*Dept of Medicine, David Geffen School of Medicine, University of California, Los Angeles, "Depts of Medicine, Epidemiology and Biostatistics, University of California, San Francisco, CA, USA, and ${ }^{\top}$ Eumedic Ltd, Hungerford, UK.

Correspondence: C.B. Cooper, Medicine and Physiology, UCLA School of Medicine, 10833 Le Conte Avenue, 37-131 CHS, Los Angeles, CA 90095-1690, USA.

Statement of Interest: Statements of interest for C.B. Cooper, J.R. Colthurst and E.C. Kleerup and the study itself can be found at www.erj.ersjournals.com/misc/statements.dtl

\section{ACKNOWLEDGEMENTS}

We would like to acknowledge the significant contributions of $\mathrm{J}$. Dermand, the study coordinator, M. Patel who administered the treatments and M. Abrazado who performed the blinded assessments 
(all Exercise Physiology Research Laboratory, University of California, Los Angeles, CA, USA).

\section{REFERENCES}

1 Bateman ED, Hurd SS, Barnes PJ, et al. Global strategy for asthma management and prevention: GINA executive summary. Eur Respir J 2008; 31: 143-178.

2 National Asthma Education and Prevention Program. Expert Panel Report 3 (EPR-3): guidelines for the diagnosis and management of asthma - summary report 2007. J Allergy Clin Immunol 2007; 120: Suppl. 5, S94-S138.

3 Hankinson JL, Odencrantz JR, Fedan KB. Spirometric reference values from a sample of the general US population. Am J Respir Crit Care Med 1999; 159: 179-187.

4 Juniper EF, O'Byrne PM, Guyatt GH, et al. Development and validation of a questionnaire to measure asthma control. Eur Respir J 1999; 14: 902-907.
5 Revicki DA, Leidy NK, Brennan-Diemer F, et al. Integrating patient preferences into health outcomes assessment: the multiattribute Asthma Symptom Utility Index. Chest 1998; 114: 998-1007.

6 Ware J Jr, Kosinski M, Keller SD. A 12-Item Short-Form Health Survey: construction of scales and preliminary tests of reliability and validity. Med Care 1996; 34: 220-233.

7 Mahler DA, Weinberg DH, Wells CK, et al. The measurement of dyspnea. Contents, interobserver agreement, and physiologic correlates of two new clinical indexes. Chest 1984; 85: 751-758.

8 Juniper EF, Bousquet J, Abetz L, et al. Identifying "well-controlled" and "not well-controlled" asthma using the Asthma Control Questionnaire. Respir Med 2006; 100: 616-621.

\section{Sarcoidosis-related pulmonary veno-occlusive disease presenting with recurrent haemoptysis}

\section{To the Editors:}

A 52-yr-old female nonsmoker presented with haemoptysis consisting of streaks of bright red blood daily for 3 weeks. She gave a 3-yr history of dry cough, episodic wheeze and mild exertional dyspnoea. The symptoms had not improved with inhaled corticosteroids (fluticasone $250 \mu \mathrm{g}$ b.i.d). The patient denied fever, sweats or weight loss and had no significant past medical history. Physical examination was unremarkable. Chest radiograph showed no focal pulmonary abnormality or obvious lymphadenopathy, and electrocardiogram was normal. Pulmonary function tests recorded a forced expiratory volume in $1 \mathrm{~s}$ (FEV1) of $2.22 \mathrm{~L}$ ( $86 \%$ predicted), a forced vital capacity (FVC) of $2.93 \mathrm{~L}$ (96\% pred) and a diffusing capacity of the lung for carbon monoxide (DL,CO) of $7.23 \mathrm{mmol} \cdot \mathrm{m}^{-1} \cdot \mathrm{kPa}^{-1}(88 \%$ pred).

Laboratory investigations showed a haemoglobin level of $12.9 \mathrm{~g} \cdot \mathrm{dL}^{-1}$, and a normal coagulation screen, metabolic screen and erythrocyte sedimentation rate $\left(21 \mathrm{~mm} \cdot \mathrm{h}^{-1}\right)$. Serum autoantibodies were negative and the angiotensin converting enzyme (ACE) level was $53 \mathrm{IU} \cdot \mathrm{L}^{-1}$ (normal range $0-52 \mathrm{IU} \cdot \mathrm{L}^{-1}$ ). High-resolution computed tomography (HRCT) of the chest showed thickening of central bronchovascular bundles and scattered, nodular, ground-glass and airspace opacities (fig. 1a). Fibreoptic bronchoscopy was requested. At $1 \mathrm{~h}$ prior to the procedure, the patient had a large haemoptysis of $200 \mathrm{~mL}$ bright red blood. Bronchoscopy showed diffuse fresh blood and grossly hyperaemic bronchial mucosa with generalised oozing from major and lobar bronchi (fig. 1b).

The patient subsequently underwent rigid bronchoscopy, bronchial biopsies and surgical lung biopsies from the left lower lobe. Histological examination of the bronchial biopsies was unremarkable. Lung biopsies demonstrated a cluster of noncaseating granulomata on the pleural surface but normal lung parenchyma and pulmonary vessels. Based on clinical, radiological and histological appearances, the patient was

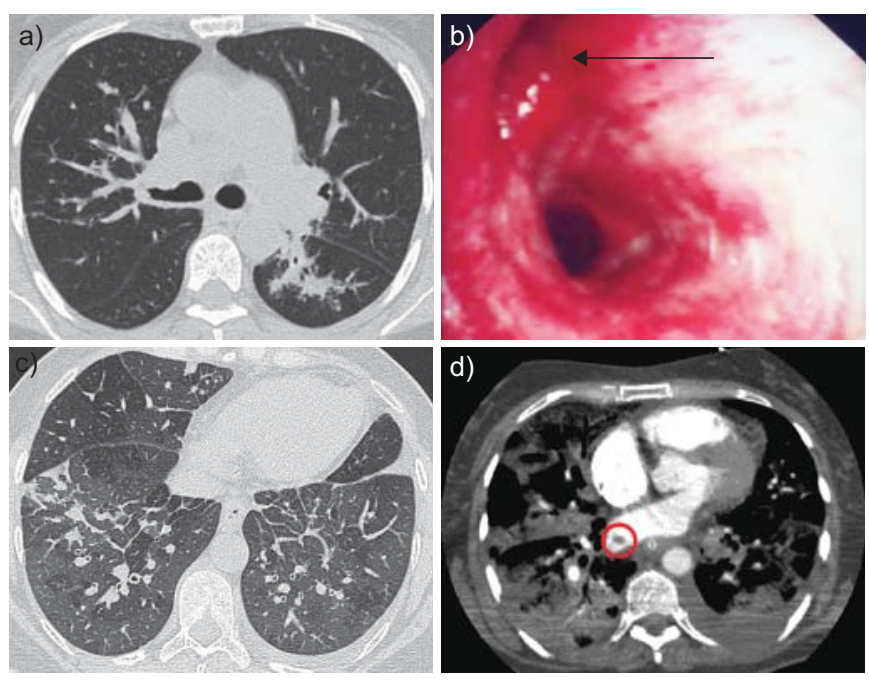

FIGURE 1. a) Axial high-resolution computed tomography (HRCT) image showing nodular thickening extending along central bronchovascular bundles in the apical segment of the left lower lobe. Elsewhere, there were scattered nodular, ground-glass and airspace opacities consistent with pulmonary sarcoidosis. b) Bronchoscopic view of the right main and right upper lobe bronchus (arrow) showing diffuse mucosal erythema. c) HRCT thorax image taken 15 months after initial presentation showing thickened interlobular septa and patchy ground-glass attenuation. The subsegmental pulmonary arteries were enlarged relative to accompanying bronchi, reflecting raised pulmonary artery pressure. There was a small left pleural effusion. d) Contrast-enhanced computed tomography pulmonary angiogram during the patient's final illness, displaying a persistent left pleural effusion with superadded bilateral, patchy airspace consolidation. In addition, a filling defect, presumed thrombus, was seen in the right pulmonary venous confluence (circled in red)

diagnosed with sarcoidosis. No specific therapy was initiated partly due to patient choice, because her symptoms had resolved and lung function tests were within normal limits. 